\title{
Performance of Nanofiltration Membrane for Printing Wastewater Treatment
}

\author{
D. W. Cheah, N. Ramlee, A. L. Desa, N. Misdan*, N. H. H. Hairom \\ Faculty of Engineering Technology, Universiti Tun Hussein Onn Malaysia, 86400 \\ Parit Raja, Batu Pahat, Malaysia
}

Submitted: 29/4/2018. Revised edition: 25/5/2018. Accepted: 28/5/2018. Published online: 4/6/2018

\begin{abstract}
Almost every manufacturing process is the major origin of wastewater with certain characteristic. Printing facility provides a wide range of waste component that is harmful to the environment and people. Those harmful waste component contains high concentration of heavy metals and dye. This paper presents one of the most promising methods to remove the heavy metals and dyes from a printing wastewater before discharging to the environment. The feasibility of commercially available NF270 membrane to treat both heavy metals and dye was thoroughly investigated. The study was carried out using a cross-flow nanofiltration membrane system at operating pressure and temperature set at 5 bar and $24^{\circ} \mathrm{C}$, respectively. Experimental results showed that the permeate flux of NF270 is decreased from 6.2 to $5.0 \mathrm{~L} / \mathrm{m}^{2} . \mathrm{h}$ after 1 -h operation. Whilst, the rejection of both iron and zinc ions could be obtained up to $96.9 \%$ and $97.8 \%$, respectively. Additionally, almost complete elimination of colour (99.6\%) could be achieved using NF270 membrane. Thus, it can be concluded that the commercial NF270 membrane is promising in removing both heavy metal ions and dye from printing wastewater.
\end{abstract}

Keywords: Printing wastewater treatment, thin film nanocomposite, nanofiltration

\subsection{INTRODUCTION}

The survival of humanity has improved over the last few decades, from merely social reproduction to the development of human sustainability. Social sustainable evolution entails as wide as improvise in the comfortability, functionality, and versatility that permeated through all class of the societies. While the human lifestyle continues sophisticating in various aspects thanks to expeditious industrialization and economic growth globally, the activities also causing drastic adversity to the environment and living organism in the world. The impacts include depletion of nonrenewable resources, threatening the survivability of the ecosystem, heavy pollution to environment, and eventually leads to backlash on human lifespan. One of the major contributor in polluting the environment is printing industry [1-2].

In printing industries, there are two types of ink production: water-based printing ink and solvent-based printing ink. Water is used as carrier in waterbased printing ink production while organic solvent is used as carrier in solvent-based printing ink. Unlike organic solvent, water is less volatile hence it does not produce any abhorrent vapor during production. Packaging industry prefers using water-based ink to print advertisements and information on their packaging. Water-based printing ink has been receiving a lot of attention in recent years as their annual 
ink consumption increment is ranging $10 \%$ to $50 \%$ [3].

Other than using water as carrier in production of ink, water is also used in cleaning the equipment before changing different tone of ink. This wastewater contains very high concentration mixture of color pigment, organic solvents, and heavy metal [1]. Every printing companies have their own method in production and different set of tone required, therefore every printing industries wastewater is different from each other.

Table 1 presents the example of characteristic of printing wastewater from three different industries. Another dangerous element from the wastewater that threaten the environment is synthetic dyes. It also known as the most challenging component to treat in wastewater because it contains complex benzoic molecular structure, which make them difficult to decompose and high chemical resistance. Besides, synthetic dyes have various types according to their chemical compound. But most of the dyes able to break down their chemical structure if heated up to 473.15K [4-5].

Table 1 Characteristic of printing wastewater from various industries

\begin{tabular}{cccc}
\hline Company & - & $\begin{array}{c}\text { Singhal } \\
\text { Brothers }\end{array}$ & UMWW \\
\hline Bussiness & $\begin{array}{c}\text { Currency } \\
\text { printing }\end{array}$ & Textile dye & $\begin{array}{c}\text { Newspaper } \\
\text { Printing }\end{array}$ \\
\hline $\mathrm{pH}$ & $12.5-13.6$ & 10.41 & $8.0 \pm 0.3$ \\
Colour & $\begin{array}{c}\text { Intense blue } \\
(3000-4000 \text { Pt- } \\
\text { Co) }\end{array}$ & Black & 24067.0 APHA \\
BOD & $8000-9400$ & & \\
(mg/L) & $21000-25650$ & - & - \\
COD & mg/L) & 4661 & $1099 \pm 3.0$ \\
TSS & $3300-4700$ & - & $92.8 \pm 3.0$ \\
$($ mg/L) & $18000-22500$ & 103000 & - \\
TDS & {$[9]$} & {$[7]$} & {$[10]$} \\
(mg/L) & & & \\
Reference & & & \\
\hline
\end{tabular}

Like printing industries, textile dyeing industries also uses water immensely in their dyeing and finishing process. Their dyeing wastewater also heavy in color and chemicals. Thus, all these industrial wastewaters require a proper treatment before they allow to discharge to the environment [6]. If the effluents did not filter before discharge into river or any groundwater, it would jeopardize the aquatic environment. Toxic elements such as heavy metal would consume by the aquatic organisms and eventually reach to human body via bioaccumulation [7].

To treat industrial wastewater, application of membrane technologies is increasingly in demand because this technology helps in retains and recovers some valuable components in the wastewater as well as reuse the aqueous solution after treatment [6]. Among the membrane technologies, ultrafiltration (UF), nanofiltration (NF) and reverse osmosis (RO) are the most commonly used technologies. Industrial application of nanofiltration is emerging into the limelight recently in the wastewater treatment field [8].

The reason NF getting more attention than the other membrane technologies is because NF able to 
operate under lower pressure than RO, thus required less energy to operate, and it has higher rejection rate compare to UF. As of now, NF is widely used to separate multivalent ionic compound with relatively low molecular weight (200-1000 $\left.\mathrm{gmol}^{-1}\right)$ from wastewater [6, 8]. Heavy metal such as iron and zinc are the example of metallic multivalent ionic compound. Thus, the objective of this study is to investigate the performance of NF270 in treating printing wastewater that contain heavy metals and dyes.

\subsection{METHODS}

\subsection{Materials}

Commercially available NF270 was purchased from Dow Filmtech Corporation. The wastewater obtained from UMWW Corporation, a company who expertise in printing and publication of newspaper. The volume of wastewater collected is $9.5 \mathrm{~L}$ and light blue in color. Table 2 shows the characteristic of the wastewater given from UMWW Corporation at $24^{\circ} \mathrm{C}$.

Table 2 Characteristic of wastewater from UMWW Corporation

\begin{tabular}{lc}
\hline Chemical properties & Value \\
\hline COD (mg/L) & 1100 \\
Turbidity (FAU) & 343.5 \\
TSS (mg/L) & 93.4 \\
pH & 8.2 \\
Color intensity (APHA) & 2412 \\
\hline
\end{tabular}

\subsection{Characterization of NF270}

The morphology of the NF270 was examined by using Scanning Electron Microscopy (SEM) analysis with an accelerating voltage of $20.0 \mathrm{kV}$. Atomic force microscopy (AFM) was used to characterize the surface morphology of the NF270 in terms of the roughness parameters. The scanning area of each membrane was $5 \mu \mathrm{m} \times 5 \mu \mathrm{m}$.

\subsection{NF Membrane Performance Evaluation}

The flux and rejection of the fabricated NF270 membrane was studied using a crossflow NF system as shown in Figure 1. The NF270 membrane was initially compacted at a transmembrane pressure difference of 6 bar with DI water for about $1 \mathrm{~h}$. The effective membrane surface area was 42 $\mathrm{cm}^{2}$. The NF experiments were then performed using printing wastewater at an operating pressure and temperature set at 5 bar and $24{ }^{\circ} \mathrm{C}$, respectively.

Membrane water flux (F) was subsequently calculated using the following equation:

$$
F=\frac{V}{t \times A}
$$

Where $\mathrm{V}$ is the permeate volume (L), A is the membrane area $\left(\mathrm{m}^{2}\right)$ and $\mathrm{t}$ is the time to obtain V (h).

Whereas, both heavy metals and dyes rejection were then determined using the following equation

$$
R(\%)=\left(1-\frac{C_{p}}{C_{f}}\right) \times 100
$$

where $C_{p}$ is the permeate concentration (ppm) and $\mathrm{C}_{\mathrm{f}}$ is the feed concentration (ppm), respectively.

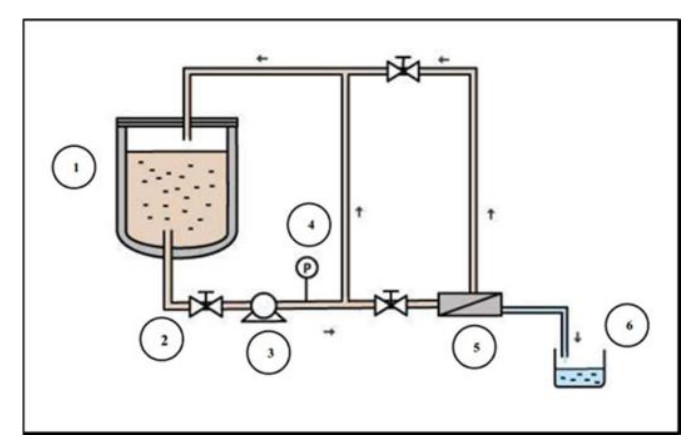

Figure 1 Schematic diagram of membrane nanofiltration process 
An ICP-OES spectrometer (Optima 8000) was used to measure the heavy metals ion concentration in the feed and permeate solutions. While an UV-Vis Laboratory spectrophotometer (DR 5000) at a wavelength of $192 \mathrm{~nm}$ was used to measure the dye concentration in the feed and permeate solutions

\subsection{RESULTS AND DISCUSSION}

\subsection{Characteristic of Membrane NF270}

The 3D image of NF270 was presented in Figure 2 with an average surface roughness value of $8.69 \mathrm{~nm}$. A common ridge and valley structure could be observed on the surface of NF 270 membrane. Likewise, this structure has also been observed on the SEM image shown in Figure 3.

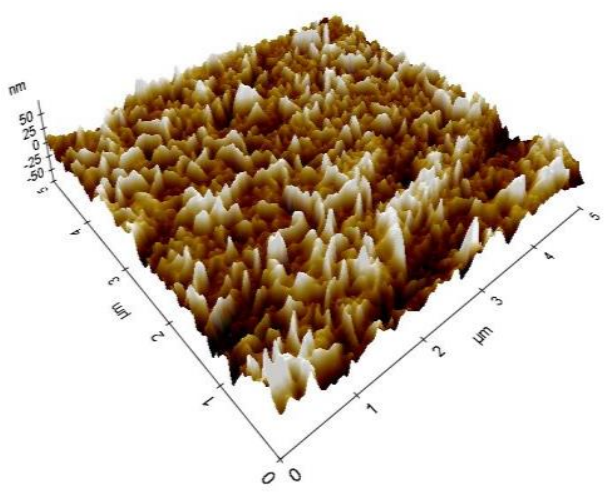

Figure 2 3D AFM image of NF270

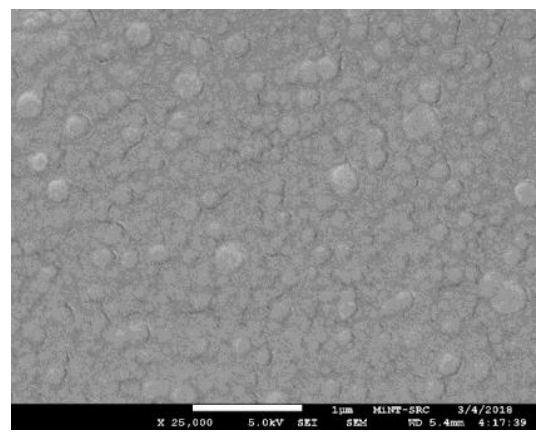

Figure 3 SEM surface image of NF270

\subsection{Permeation Flux of NF270}

As can be depicted from Figure 4, the permeate flux was gradually decreased from 6.286 LMH to 5.017 $\mathrm{LMH}$ as the time increased. This mainly due to the formation of membrane fouling on top of the membrane surface. When the pores of membrane started to block by foulants, the permeate flux plummeted down sharply. After 30 minutes, foulants start to aggregate each other and the development of rapid cake formation occurs, and thus, the permeate flux decline relatively constant $[11,12,13]$.

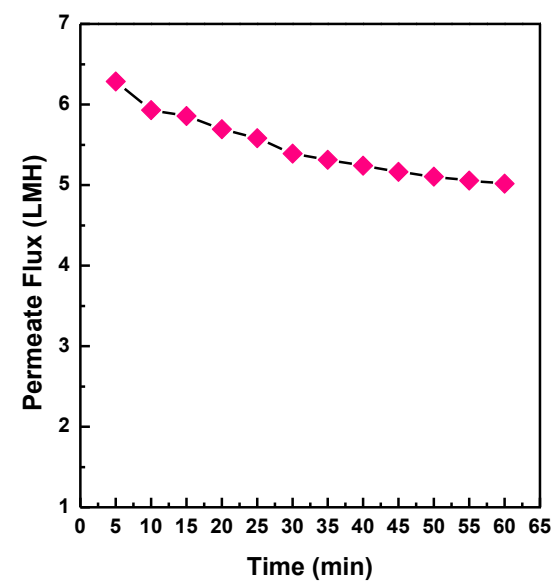

Figure 4 Permeate flux of NF270

\subsection{Heavy Metal Ions Rejection of NF270}

It was detected that the printing wastewater contains Iron $(\mathrm{Fe})$ ion and Zinc $(\mathrm{Zn})$ ion. The initial feed concentration of $\mathrm{Fe}$ ion and $\mathrm{Zn}$ ion were $15.8082 \mathrm{mg} / \mathrm{L}$ and $14.956 \mathrm{mg} / \mathrm{L}$, respectively. After treated with membrane nanofiltration process, the concentration of both ions were decreased tremendously. $\mathrm{Fe}$ ion concentration in treated water is ranging from $0.333 \mathrm{mg} / \mathrm{L}$ to $0.342 \mathrm{mg} / \mathrm{L}$. Whereas, $\mathrm{Zn}$ ion concentration in treated water is ranging from 0.473 $\mathrm{mg} / \mathrm{L}$ to $0.459 \mathrm{mg} / \mathrm{L}$. Thus, the heavy 
metal ions rejection could be achieved up to $96.93 \%$ for Fe ion and $97.79 \%$ for

Zinc ion at an operating time of 1 hour, as can be seen in Figure 5. NF270 has negative surface charge that able to attract any positive ion such as iron ion and zinc ion. This attraction with the steric effect causing the ions attached on the membrane surface without passing through. As soon as the accumulation of heavy metal ions increase, the membrane is topped with a layer of positive charged ion. This positive charged ion will aid the membrane in preventing other positive heavy metal ion to approach the membrane [13].

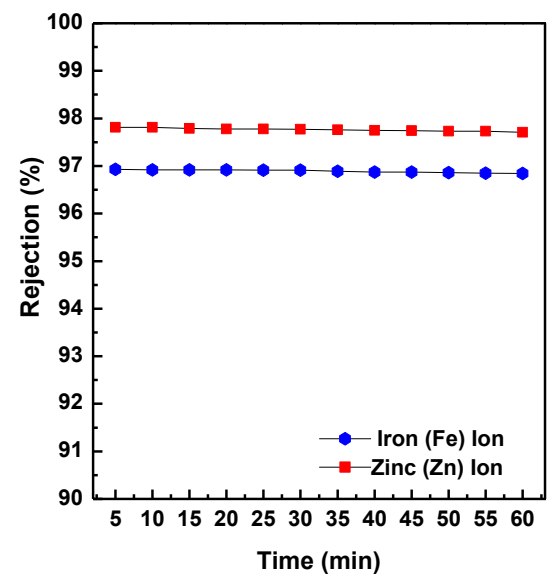

Figure 5 Heavy metal ions rejection at an operating pressure of 5 bar and operating time of 60 minutes

\subsection{Dye Rejection of NF270}

Figures 6 shows the rejection of dye during 60 minutes of operating time. The dye rejection increased gradually from $96.4 \%$ to $99.6 \%$. This may probably due to the membrane pore blockage by foulants which subsequently, increased the rejection of dyes when increased the operating times $[10,11,12]$.

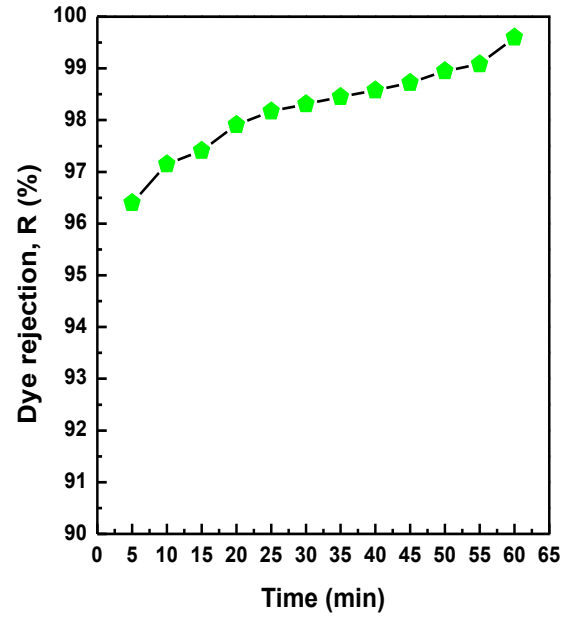

Figure 6 Dye rejection at an operating pressure of 5 bar and operating time of 60 minutes.

\subsection{CONCLUSION}

The permeate flux decreased from 6.3 $\mathrm{LMH}$ to $5.02 \mathrm{LMH}$ after 1 hour of operating time. This is mainly due to membrane fouling that plays a major causative agent in decline of permeate flux during filtration process. Whilst, the rejection rate of nanofiltration process is very promising with $96.93 \%$ of iron ion rejection, $97.79 \%$ of zinc ion rejection, and $99.64 \%$ of dye rejection rate. Thus, it is the nanofiltration membrane process is a highly recommended method for treating industrial printing wastewater as it has high rejection rate for both heavy metals and dyes with a driving pressure much lower than reverse osmosis.

\section{ACKNOWLEDGEMENT}

The financial support from Ministry of Higher Education (MOHE) under the FRGS scheme (Vot. no.: 1617) and Universiti Tun Hussein Onn Malaysia under STG scheme (Vot no.: U654) are gratefully acknowledged and appreciated. The authors would also 
like to thank Advanced Membrane Technology Research Center (AMTEC) UTM, Johor for providing facilities and guides to finish this project.

\section{REFERENCES}

[1] J. S. Kiurski, Kiurski, B. B. Marić, S. M. Aksentijević, I. B. Oros \& V. S. Kecić. 2016. Occupational Hazards in Printing Industry. Int. J. Environ. Sci. Technol. 13(3): 955-972.

[2] C. Li, Y. Liang \& Y. Chen. (2005). Combined Ultrafiltration and Suspended Pellets for Lead Removal. Separation and Purif. Technol. 45(3): 213-219.

[3] L. Khannous, A. Elleuch, I. Fendri, N. Jebahi, H. Khlaf \& N. Gharsallah. 2015. Treatment of Printing Wastewater by a Combined Process of Coagulation and Biosorption for a Possible Reuse in Agriculture. Desalination and Water Treatment. 57(13): 5723-5729.

[4] M. F. Abid, M. A. Zablouk \& A. M. Abid-Alameer. 2012. Experimental Study of Dye Removal from Industrial Wastewater by Membrane Technologies of Reverse Osmosis and Nanofiltration. Iranian Journal of Environmental Health Science \& Engineering. 9(1): 17.

[5] X. Zheng \& J. Liu. 2006. Dyeing and Printing Wastewater Treatment using Membrane Bioreactor with a Gravity Drain. Desalination. 190(1-3): 277-286.

[6] S. Chakraborty, S. De, J. Basu \& S., Das Gupta. 2005. Treatment of a Textile Effluent: Application of a Combination Method Involving Adsorption and Nanofiltration. Desalination. 174(1): 73-85.

[7] K. L. Patil \& C. P. Sawant. 2009. An Evaluation of Heavy Metals Content in Dyeing and Printing Industrial Effluents in GIDC Surat: A Statistical Approach. Asian Journal of Chemistry. 21(9): 7097-7100.

[8] D. Bessarabov \& Z. Twardowski. 2002. Industrial Application of Nanofiltration-New Perspectives. Membrane Technology. 2002(9): 6-9.

[9] N. Tapas, S. Sunita, P.P. Oathe, \& S. N. Kau. 2003. Pre-Treatment of Currency Printing Ink Wastewater Through Coagulation-Flocculation Process. Water, Air, and Soil Pollution. 148(1): 15-30.

[10] N. H. H. Hairom, A. W. Mohammad \& A. A. Kadhum. 2014. Nanofiltration of Hazardous Congo Red Dye: Performance and Flux Decline Analysis. Journal of Water Process Engineering. 4: 99-106.

[11] C. Fersi, L. Gzara, M. Dhahbi. 2009. Flux Decline Study for Textile Wastewater Treatment by Membrane Processes. Desalination. 244: 321-332.

[12] M. R. Wiesner, P. Aptel. 1996. Mass Transport and Permeate Flux and Foulind in Pressuredriven Process. Water Treatment Membrane Handbook. McGrawHill, New York.

[13] X. Liu, \& W. Wang. 2012. The Application of Nanofiltration Technology in Recovery of Ionic Liquids from Spinning Wastewater. Applied Mechanics and Materials. 178-181, 499-502. 